\title{
Publicações em Revista (*)
}

Formação e Selção dos Funcionários Locais, edição de 1959 do D.A.S.P. e do Instituto Brasileiro de Ciências Administrativas, formato $22 \times 15$ e 126 parinas, é urı tese do Sr. Manoel Caetano Bandeira de Niello, diretor do Serviço de Ducumentação do D.A.S.P., apresentada como contribuiçáo do Brasil an II Congresso Ibero-Americano de Municipios, realizado $\mathrm{em}$ Lisboa, de 14 a 19 de niaio de 1959 , e do qual o $\mathrm{Sr}$. Bandeira de Mello foi relator do tema $n^{\circ}$ 2. A publicação em epígrafe inclui, além da tese brasileirą $e$ do temário do Congresso, interessante anexo sôbre o sistema do mérito :a Prefeitura de Belo Horizonte.

A tese do Sr. Bandeira de Miello ocupa vinte páginas da publicação examinada, analisando inicialn:ente a ampliação das funções estatais e estendendo-se pelo exame da administração de pessoal, como mecanismo básico do catálogo dos objetivos prioritários do Govêrno; são registrados os três elementos do sistema de coordenação executiva: capacidade, conjuntuta de eficiência e mérito, êste último imperativo democrático. Salienta o trabalho que, apesar da decisiva e renovaciora contribuição do D.A.S.P. e do I.B.A.M., não está "ganha a luta contra o empreguismo na administração pública. As chamadas clientelas eleitorais, nascidas do exercício do regime democrático, vocação inarredável do povo brasileiro, contribuem, por uma distorção fàcilmente explicável pelas condições econômicas e sociais infelizmente ainda reinantes, para que haja pletora nos quadros administrativos".

Adiante, vinculando o rendimento da máquina burocrática estatal ao desenvolvimento do país, o autor delineia a importância do sistema do mérito em face do impacto da revolução tecnológica, da expansão demográfica, da urbanização. E é no âmbito municipal que se torna imperativa a implantação do "inérito", pela integração do govêrno local na realidade direta da coletividade. São quatro, segundo o autor, as vantagens da introdução do sistema: imunidade contra influência politica, seleção inicial dos mais capazes, apuraçâo imparcial da eficiência em serviço e promoção baseada no merecimento, além, naturalmente, de constituir critério de aferição da produtividade didática e do grau de adaptaçăo dos currículos à realidade nacional.

Continuando, o Sr. Manoel Caetano Bandeira de Mello desfila as vantagens que o concurso apresenta para o estudante, os pais, os professôres, o cidadão, os chefes, o pais enfim. Antes de enumerar as 4 fases do

(*) Transcrito da Revista Notícias Municipais. 
processo de seleção, assinala o autor os óbices ao concurso: o "coronelismo" no hinterland e o vedetismo político no meio urbano. "Perspectivas" é o tópico seguinte da tese: preconiza-se a transposição para o âmbito municipal da experiência federal do D.A.S.P., através da esquematização e concretização do movimento racionalizador na administração de pessoal, como fator do desenvolvimento planejado, ideologia e estratégia do municipalismo. A transplantação referida para a jurisdição municipal é problemática, sendo necessário primeiro erradicar a interinidade.

Como conclusões ao tema relatado, o Sr. Manoel Caetano Bandeira de Mello apresenta os seguintes itens, aprovados por unanimidade pelo Congresso: instituição de um órgão de pessoal nas municipalidades que não o possuem; implantação de plano de classificação de cargos baseado na análise científica do trabalho e consoante o princípio de salário igual para trabalho igual; adoção do sistema do mérito, aferido através de prova pública e estágio probatório; institucionalização do treinamento funcional; elaboração de estatuto dos funcionários municipais; regime de colaboração de outras esferas de govêrno, respeitada a autonomia municipal.

IBBD: Orçamento-Programa para 1960. Impresso em multilith. com 94 fôlhas, num formato que dificulta o manuseio $(33,5 \times 21,5)$, trata-se da proposta orçamentária estimada para o exercício de 1960 do Iristituto Brasileiro de Bibliografia e Documentação, apresentada pelo diretor do Serviço de Administração, órgão regimental de orçamento no I.B.B.D. Para a elaboração do orçamento-programa o I.B.B.D. foi assessorado por uma equipe de técnicos da Fundação Getúlio Vargas, orientada pelo Prof. José Teixeira Machado Jr. e integrada, entre outros, pelos professôres Aluizio Loureiro Pinto e Jorge Gustavo da Costa.

A introdução assinada pelo diretor do S.A. coloca o problema do orçamento-executivo, que, na era do administrador profissional, deve ser distinto do orçamento-politico, caracterizado pela tomada de decisão, competência própria do Conselho Diretor. Adotada a "politica orçamentária" segundo tim programa geral, a fase executiva será dinamizada, dentro da mecânica orçamentária, pela globalidade das dotações, pelo rigorismo da estinativa etc.

Vinculando o estabelecimento do programa à tarefa de tomada de contas (verificação objetiva), a introdução examinada desfila vantagens do "orçamento-programa": integração do contrôle no ciclo orçamentário, objetivismo dos relatórios, publicidade concreta do destino da carga tributária,

A estimativa das despesas com pessoal, como elemento de custo, não levou em conta, por deficiência dos métodos de análise, o relacionamento do volume de trabalho (utilização da relação "homem-hora" para "unidade de trabalho"). Espera-se, contudo, chegar a tal aperfeiçoamento, desde que já foi possivel, no orçamento do presente exercício, trabalhar no nivel de seção para a contabilização de custos da despesa com pessoal.

Acredita a direção do I.B.B.D. ser possivel utilizar o orçamento como instrumento de administração e apresenta o trabalho pioneiro ora realizado 
à consideraçãe dos "organismos públicos brasileiros interessados no constante aperfeiçoamento das técnicas administrativas".

O "Sumário das Despesas" apresenta o modo pelo qual o I.B.B.D. pretende gastar, em 1960, o volume de suas receitas, ou seja ........... Cr\$ 43.263.000,00. Foi feita uma classificação em despesas correntes (gastos diretos e indiretos) e despesas de capital. As despesas correntes atingem a C.r $\$ 34.500 .000,00$, sendo $\operatorname{Cr} \$ 29.223 .314,00$ de gastos diretos e Cr $\$ 5.276 .686,00$ de gastos indiretos. Para despesas de capital conta o I.B.B.D. com Cr\$8.763.000,00. O quadro analítico da Despesa revela algumas particularidades: foi feita uma classificação por unidade administrativa, estando os recursos distribuidos por sete atividades especificas, correspondentes aos setores administrativos, e mais administração. Assiri, 83\% das despesas orçamentárias do I.B.B.D. em 1960, segundo o programa examinado, serão destinados à realização dos programas setoriais das sete unidades-fins do Instituto, ficando $17 \%$ para despesas de administração (que não incluem Pessoal: êste item representa $52 \%$ da despesa total). O quadro denota, assim, a identificação dos programas com as unidades setoriais do I.B.B.D., sem que os 43 milhões de crizeiros estejam distribuidos segundo um plano real de realizações. A integração intersetorial no estabelecimento de um orçamento-programa exige o esquecimento do organograma da instituição, o que não foi realizado. Parece que os autores do orçamento prepararam o programa debruçados sôbre o organograma do I.B.B.D.

O documento em exame inclui dois gráficos estatísticos mostrando o percentual das despesas correntes por objeto ("Pessoal - 52,20\%; "Matërial de Consumo e de Transformação" - 8,69\%; "Serviço de Terceiros" - 25.81\%; "Encargos Diversos" - 13,18\%; "Transferências" - 0,12\%) e a distribuição também percentual das despesas orçamentárias pelas unidades de serviço, onde a maior parcela destina-se ao Serviço de Informações Técnico-Cientificas $(27,72 \%)$ e a menor à Administração Superior $(4,76 \%)$. Seguem-se nove capítulos contendo a discriminação cos gastos diretos orçados para as diversas unidades da administração, com uma insólita inclusão da relação de atribuições de cargos e órgãos, acompanhada do respectivo "programa de atividades". A discriminação de atividades apresenta razoável especificidade na fixação de quantitativos para a realização dos diversos itens programados, chegando-se, em alguns casos, ao custo unitário (fichas, páginas, aulas etc.). Cada capítulo inclui demonstrativos classificando a despesa por elemento e por função, seguindo-se um resumo dos quantitativos fixados.

Há ainda, no final da publicação examinada, três capitulos sôbre a discriminação dos gastos indiretos do I.B.B.D. em 1960, caracterizados em três parcelas (Encargos Gerais, Contingências e Transferências) e completados por uma análise da distribuição dos gastos indiretos. Tais custos não foram apropriados diretamente pelos diversos serviços do I.B.B.D.: preferiu-se o critério do rateio do total pelos setores com base no quantitativo de despesas diretas apuradas no orçamento. Utilizando sistema bastante comum em organizações industriais, os técnicos da Fundação, embora não 
justifiquem a decisão, adotaram o "fator de proporcionalidade" de 0,180564 , cociente da divisão do volume global de gastos indiretos $(5.276 .686,00)$ pelo total geral de gastos diretos do I.B.B.D. (29.223.314,00). Como não existe no Brasil experiência de contabilidade de custos no setor público da adninistração, torna-se difícil avaliar até que ponto tal critério é válido para a determinação do indice real de onerosidade dos gastos indiretos sôbre o custo dos serviços ou atividades específicas da organização. E' evidente a importância de tal consideração quando verificamos que o total dos gastos indiretos do I.B.B.D. representam cêrca de $12 \%$ do volume global da despesa do Instituto no corrente ano, ou seja, aproximadamente tôda a despesa com o Serviço de Administração. O empirismo do critério adotado evidencia-se pela impossibilidade de avaliar a maior ou menor incidência do "gasto direto" nos serviços. A unidade Serviço de Informações Técnico-Cientificas, por exemplo, está sobrecarregada com $4,7 \%$ de tais gastos, correspondendo à maior incidência numa escala que vai até $0,84 \%$ para Administração Superior.

Finalmente, constituindo o orçamentc do I.B.B.D. não exatamente um "orçamento-programa" mas sim um "orçamento funcional" onde se procurou com êxito, maior rigorismo na classificação das contas, objetividade na apresentação do documento e clareza na atribuição de verbas, ingressa o trabalho do I.B.B.D. no decisivo processo de tecnização da administração pública no Brasil, que, neste início de década, já conta com experiências renovadoras, como o PAG, a SUDENO, o Plano Nacional da Industria de Tratores e outros. - Álvaro C. Silva. 